\title{
ATIVIDADES EXPERIMENTAIS DE ELETRODINÂMICA CONSTRUÍDAS POR ALUNOS COM DEFICIÊNCIA VISUAL
}

\author{
EXPERIMENTAL ELECTRODYNAMIC ACTIVITIES BUILT BY BLIND STUDENTS \\ TÍTULO EM ESPANHOL TÍTULO EM ESPANHOL TÍTULO EM ESPANHOL TÍTULO EM \\ ESPANHOL
}

\section{Fábio Lombardo \\ Evangelista \\ (iD) 9}

Mestre em Educação Científica e

Tecnológica (UFSC)

Professor no Instituto Federal

Catarinense (IFC)

fabio.evangelista@ifc.edu.br

\section{Stênio Severino da Silva (iD)}

Mestre em Educação Profissional e Tecnológica (IFSC)

Técnico em Assuntos

Educacionais no Instituto Federal

Catarinense (IFC)

stenio.silva@ifc.edu.br

\begin{abstract}
Resumo
Os estudantes com deficiência visual carecem de abordagens didáticas que os incluam no ambiente de ensino regular. $\mathrm{O}$ objetivo dessa pesquisa é a elaboração e análise de uma proposta para discutir conceitos clássicos de Eletrodinâmica, junto a estudantes com essa especificidade. Para tanto, adotou-se a abordagem qualitativa, delineada pelo Estudo de Campo, no qual, a partir da coleta de dados e análise do material de um ensaio piloto, foram construídas as categorias de análise e reelaborada uma nova sequência didática para ser aplicada posteriormente. A partir de atividades experimentais, categorizadas na literatura, foram desenvolvidas algumas adequações ao material e ao procedimento metodológico para a planejamento piloto, aplicado junto à Associação Catarinense de Integração do Cego (ACIC) com a participação de seis alunos com deficiência visual e com idades entre 20 e 35 anos. As avaliações da pertinência destes materiais e do procedimento apresentaram-se como essenciais à reestruturação de uma segunda sequência didática. Como resultado, aponta-se algumas características dos materiais e procedimentos, consideradas relevantes para o auxílio no processo de ensino e aprendizagem de estudantes com e sem deficiência visual no ensino regular.

Palavras-chave: Atividades Experimentais. Ensino de Física. Alunos com Deficiência Visual. Inclusão.
\end{abstract}

Recebido em: 30 de agosto de 2020.

Aprovado em: 22 de março de 2021.

Como citar esse artigo (ABNT):

EVANGELISTA, Fábio Lombardo; SILVA, Stênio Severino da. Atividades experimentais de eletrodinâmica construídas por alunos com deficiência visual. Revista Prática Docente, v. 6, n. 1, e010, 2021.

http://doi.org/10.23926/RPD.2021.v6.n1.e010.id906 


\begin{abstract}
Blind students lack didactic approaches that include them in the regular teaching environment. The objective of this research is to elaborate and to analyze a proposal and discuss the classical concepts of Electrodynamics with students, with this specificity. To this end, the qualitative approach was adopted, outlined by the Field Study, in which, from the collection of data and analysis of the material of a pilot trial, the categories of analysis were constructed and a new didactic sequence was reworked to be applied later. Based on experimental activities, categorized in the literature, some adaptations were made to the material and methodological procedure for pilot planning, applied to the Associação Catarinense de Integração do Cego (ACIC) with the participation of six blinded students and aged between 20 and 35 years. The assessment of the relevance of these materials and the procedure proved to be essential to the restructuring of a second Didactic Sequence. As a result, some characteristics of the materials and procedures are pointed out, considered relevant to help in the teaching and learning process of students with and without blindness in regular education.
\end{abstract}

Keywords: Experimental activities. Physics education. Blind students. Inclusion.

\title{
Resumen
}

Los estudiantes con discapacidad visual carecen de enfoques didácticos que los incluyan en el entorno docente habitual. El objetivo de esta investigación es la elaboración y análisis de una propuesta para discutir conceptos clásicos de Electrodinámica, con estudiantes con esta especificidad. Para ello, se adoptó el enfoque cualitativo, perfilado por el Estudio de Campo, en el cual, a partir de la recolección de datos y análisis del material de un ensayo piloto, se construyeron las categorías de análisis y se elaboró una nueva secuencia didáctica para ser aplicada posteriormente. A partir de actividades experimentales, categorizadas en la literatura, se realizaron algunos ajustes al procedimiento material y metodológico para la planificación piloto, aplicado a la Associação Catarinense de Integração do Cego (ACIC) con la participación de seis estudiantes con discapacidad visual de edades comprendidas entre 20 y 35 años. Las valoraciones de la pertinencia de estos materiales y el procedimiento fueron fundamentales para la reestructuración de una segunda secuencia didáctica. Como resultado, se señalan algunas características de los materiales y procedimientos, considerados relevantes para ayudar en el proceso de enseñanza y aprendizaje de los estudiantes con y sin discapacidad visual en la educación regular.

Palabras clave: Actividades experimentales. Enseñanza de la física. Estudiantes con discapacidad visual. Inclusión. 


\section{INTRODUÇÃ̃o}

É importante ter uma compreensão adequada acerca da pessoa com deficiência visual e o que a torna específica. Camargo (2005) afirma que atitudes consideradas simples para uma pessoa com visão normal, como tomar um ônibus, escolher o que comer em um restaurante, contar dinheiro, ter acesso a informações e frequentar uma sala de aula, se constituem como extremamente complexas, inéditas, extraordinárias, anormais e constrangedoras às pessoas com esta particularidade. Tais especificidades, em algumas situações, são esquecidas, ignoradas, ou ainda, submetidas a um fator místico, que atribui a estas pessoas uma alta sensibilidade, refletida num tipo de "sexto sentido". Na sociedade de maioria vidente, a iniciativa sempre foi a de tentar fazer com que as pessoas com deficiência visual se adequassem à realidade da cultura dominante. "Seria absurdo negar este fato, antes, ele deve ser considerado para que se possam identificar os conceitos, valores, definições de senso comum ditado pelo sentido da visão" (MASINI, 1994 p. 27). Em outras palavras, poderia se dizer que a existência dos que não possuem a capacidade de enxergar é ditada por aqueles que a possuem.

Trabalhos indicam que estudos nessa seara encontram-se em andamento (PIMENTEL e ARAGON, 2019; DE SOUZA e PALMA, 2017; CARNEIRO et al., 2017; LIMA e DE CASTRO CATARINO, 2012), indicando também que não se pode negar ou ignorar a necessidade de uma maior atenção à efetivação social destes sujeitos. Para atender a esse contingente, políticas inclusivas foram desenvolvidas e postas em prática, como a Lei de Diretrizes e Bases da Educação (LEI No. 9394/96, Artigo $4^{\circ}$ ), que defende a entrada e permanência destes alunos ao ensino oferecido pelas escolas e classes regulares públicas. No entanto, provavelmente, professores que não possuem formação específica terão contato com estes alunos nas suas salas de aula. Faz-se importante, portanto, capacitá-los sobre como atuarem com esse público específico. Neste sentido, este trabalho proporciona um exemplo de uso de materiais didáticos e aplicações de atividades experimentais a fim de auxiliar a prática docente no contexto de alunos com deficiência visual.

Assim sendo, emerge a seguinte pergunta: Quais características devem conter as atividades experimentais de modo a auxiliar o ensino de eletrodinâmica para estudantes com deficiência visual?

Neste viés, o presente artigo tem a intenção de indicar um possível caminho para trabalhar corrente elétrica, diferença de potencial elétrico e resistência elétrica para alunos com deficiência visual. A percepção acerca da relevância do tema surgiu de uma reunião com a 
Coordenação Pedagógica da Associação Catarinense de Integração do Cego (ACIC), na qual chegou-se à conclusão de que conteúdos vinculados à Eletricidade seriam mais interessantes aos seus alunos. Nesta perspectiva, a preocupação foi desenvolver uma sequência didática com características que permitisse o ensino do referido conteúdo para alunos com deficiência visual, mas que, por outro lado, também pudesse ser aplicada concomitantemente aos alunos videntes.

\section{APORTe TeÓRICO.}

A relevância do senso comum dos estudantes durante o processo de ensinoaprendizagem é algo amplamente difundido. Pietrocola (2001) explica que o senso comum, configurado a partir do histórico de vida de cada pessoa, é delineado por um contexto repleto de crenças, ideais, tradições familiares e culturais, que modificam seu modo de pensar e agir, num mútuo ajuste entre o mundo exterior e interior.

Como base nessa percepção, procurou-se durante todo o processo de aplicação da sequência de ensino, levar em conta o que as pesquisas, no ensino científico, afirmam sobre o levantamento das pré-concepções - também chamadas concepções alternativas, ideias intuitivas, concepções espontâneas, etc.: - (COLL et al., 1998; VIENNOT, 1979; SOLIS VILLA, 1984; DRIVER, 1986).

Coll et al (1998), salienta que existe um caráter implícito no desenvolvimento do senso comum, mostrando assim que, nem sempre o indivíduo tem consciência da existência de suas concepções.

Greca e Moreira (2002) acrescentam que, as concepções alternativas dos estudantes têm significado e funcionalidade para as situações cotidianas, sendo, portanto, resistentes a mudanças, representando um modo mais abrangente de se compartilhar significados, permitindo a comunicação entre vários grupos de diferentes culturas.

Apesar da já reconhecida relevância do senso comum dos alunos durante do processo de ensino-aprendizagem, pesquisas mais recentes mostram que o pensamento pouco ou nada mudou com relação a necessidade da utilidade do senso comum no aprendizado do estudante (HOFFMANN, 2017; SANTOS, 2017; OLIVEIRA, 2018; FACCIO, 2019).

Ao direcionar a atenção para o indivíduo com deficiência visual, Camargo (2005) salienta que, de maneira similar ao vidente, ele acumula experiências de todo o tipo, passando a exigir não apenas o entendimento de situações particulares, mas também do mundo em que vive. Desse modo, durante todos os encontros, os alunos foram previamente questionados sobre os fenômenos envolvidos em cada atividade, na prerrogativa de que contextualizarem e 
atribuírem significados aos conceitos trabalhados, para em seguida, dar prosseguimento à intervenção.

\subsection{ATIVIDADES EXPERIMENTAIS}

Este trabalho amparou-se no conceito desenvolvido por Alves Filho (2000), destinado ao processo de ensino e aprendizagem, denominado Atividades Experimentais. Estas atividades devem ser entendidas como um objeto didático, produto de uma Transposição Didática, de modo que tenha a função de mediar o processo de ensino-aprendizagem. É um objeto de ação que, manipulado didaticamente pelo professor, irá facilitar a indução do fenômeno didático que objetiva o ensino de saberes.

Sendo assim, a atividade experimental exige a intervenção do professor a qualquer momento, através de questionamentos, desafios, estímulos e motivações no intuito de aumentar a função ativa do aluno. Esta ideia enfatiza a inexistência de uma receita prescritiva, pois isto definitivamente barraria a espontaneidade do processo, retornando ao modelo tradicional e dogmático, no entanto, não impede que se apontem caminhos.

Pinho Alves (2000) classifica as atividades experimentais em sete categorias, das quais, quatro foram selecionadas para poder trabalhar com a bagagem intelectual dos estudantes com deficiência visual fora de um contexto escolar, moldadas pelo contorno informal de educação: Atividade Experimental Compartilhada, Modelizadora, Crítica e Comprobatória.

\subsection{AdEQUAÇÃo DAS CATEgorias}

No âmbito desta pesquisa, a Tecnologia Assistiva teve um caráter indispensável. Tratase de um conceito proposto pelo Comitê de Ajudas Técnicas (CAT), uma comarca que "estuda essa área do conhecimento no âmbito da Secretaria Especial dos Direitos Humanos da Presidência da República (SEDH/PR)" (GALVÃO FILHO, 2009, p.115).

Em suma, entende-se Tecnologia Assistiva como uma área do conhecimento interdisciplinar, que inclui produtos, serviços, práticas, estratégias, recursos e metodologias com o intuito de permitir e fomentar a autonomia e inclusão social de sujeitos com qualquer tipo de deficiência (CAT, 2007).

Os instrumentos, embasados por esta Tecnologia, podem atuar como mediações às pessoas com deficiência visual, auxiliando na potencialização da interação social. Tal interação é entendida neste artigo como a necessidade de relacionar-se, de entender e ser entendido, de 
comunicar-se com os demais, impulsionando o seu desenvolvimento (GALVÃO FILHO, 2009).

Ao se basear nas categorias de Pinho Alves (2000), é importante lembrar que elas foram pensadas para os videntes, que têm a capacidade de definir um objeto ou situação rapidamente, tanto na sua composição quanto na configuração dos seus contornos. Portanto, para os estudantes com deficiência visual, duas destas categorias foram entendidas de forma diferente, senão, adaptadas para este novo estudante. Deste modo, ao se referir ao manuseio dos materiais, houve a categorização em atividades de compartilhamento e comprobatória.

O compartilhamento vem ao encontro das muitas dificuldades originadas das diferentes interpretações que os estudantes elaboraram sobre o que manuseavam. A prática docente mostrou que os estudantes relutavam em perguntar os significados dos materiais desconhecidos. Aliou-se a isto a limitação atribuída ao sentido tátil, originando interpretações, na maioria das vezes, totalmente distintas. Por vezes, o discurso docente ainda levava o estudante a imaginar coisas desvinculadas do objeto focado. O compartilhamento traz a necessidade de se oferecer condições para que os estudantes consigam perceber um dado elemento da mesma maneira. Para isto, o professor induziu o perceber tátil dos estudantes, levando-os às relações táteis de interesse. Através da respectiva indução didática, direcionaram-se as proposições livres dos alunos, no sentido das proposições de aceitação coletiva.

Esta categoria ainda tem a importância de precursora da atividade modelizadora, crítica e comprobatória, pois é certo que, sem a assimilação tátil do concreto, dificultaria-se, senão, inviabilizaria-se a assimilação conceitual proveniente da relação mediadora entre as demais atividades e os conceitos científicos.

Já a comprobatória, assemelha-se a um exercício tradicional de repetição, só que mais rico, pois adiciona à manipulação a memorização dos equipamentos, assegurando a construção de um modelo mental do percebido. O material manuseado não deve ser novidade ao estudante, para assim, atuar como um reforço, uma revisão tátil oferecendo condições de sua utilização em novas situações.

Entretanto, é importante ressaltar que estas duas atividades táteis, de compartilhamento e comprobatória, servem de base para se alcançar às categorias de Pinho Alves (2000), funcionando como um trampolim, assegurando o acesso aos dados do equipamento e à construção dos saberes 


\section{Metodologia da PESQUiSA}

A metodologia na qual se delineou esta pesquisa apresenta características de estudo de campo. Embora existam procedimentos comuns nesses estudos, não pode-se definir rigorosamente etapas a serem seguidas. A especificidade de cada estudo acaba por definir os próprios procedimentos. No entanto, existem algumas etapas que, em grande parte dos estudos dessa natureza, podem ser observadas (GIL, 2002). No presente trabalho foi elaborado um projeto inicial enquanto o pesquisador realizou uma exploração preliminar de campo, com visitas à Associação Catarinense de Integração do Cego (ACIC). Desse modo, formulou-se o projeto de pesquisa, para então aplicar o projeto-piloto na forma de um pré-teste dos instrumentos e procedimentos de pesquisa. A partir da coleta de dados e análise do material, foram construídas as categorias de análise e reelaborada a sequência didática a ser aplicada ao final.

Nos estudos de campo há utilização de instrumentos como questionários e observação, tornando-se necessário aplicá-los previamente antes de sua utilização e, dessa forma, desenvolver os procedimentos de aplicação, testar o vocabulário utilizado nas questões e assegurar-se de que as observações feitas possibilitem verificar as variáveis que se pretende medir. Cabe ressaltar que se faz necessário que o pré-teste seja feito com população semelhante à que será estudada (GIL, 2002).

Estudos de campo tendem a utilizar diferentes formas de coleta de dados, em que os procedimentos de análise costumam ser predominantemente qualitativos.

O contato inicial com os estudantes com deficiência visual originou-se da carência na formação acadêmica de Licenciatura em Física para este fim (EVANGELISTA, 2019). Sabendo que a constituição respalda a entrada e permanência de todas as pessoas ao ensino público, percebeu-se a importância das variáveis envolvidas na forma com que estes alunos interagem e reconhecem o mundo a sua volta, como utilizam o material didático e como expressam suas dificuldades ao lidar com o conteúdo físico estudado. Este aspecto refletiu na observação da aprendizagem dos estudantes, levando-se em consideração todo o processo de aplicação e não apenas determinados pontos.

A opção por uma análise fenomenológica surgiu como uma opção para a compreensão dos acontecimentos, de maneira a direcionar a atenção da pesquisa muito mais para o processo do que para o produto. De igual forma, a abordagem de natureza qualitativa da pesquisa 
(FREITAS, 2016) pareceu ser a mais apropriada para a análise dos fenômenos educacionais vivenciados.

Tal abordagem culminou em uma estratégia para a condução da sequência, composta por cinco procedimentos:

1. Adequação das atividades experimentais a fim de permitir interações não visuais.

2. Utilização de um processo metodológico que respeitasse as características sensoriais dos alunos com deficiência visual.

3. Aplicação das referidas atividades a um grupo de alunos com deficiência visual, seguido pelo registro e análise (sequência piloto).

4. Correção e reformulação da sequência didática, dos equipamentos e do procedimento metodológico utilizado.

5. Reaplicação das atividades, agora reformuladas, a um novo grupo de alunos com deficiência visual, seguido pelo registro e análise (sequência final).

Em suma, primeiramente foi desenvolvida e aplicada uma sequência piloto. Após avaliar a pertinência dos materiais didáticos e procedimentos utilizados, houve uma reestruturação, resultando em uma nova sequência, planejada e aplicada a outros alunos.

\section{ENSAio PILOTO}

O ensaio piloto foi composto por cinco encontros. A sequência didática arquitetou-se da seguinte forma: $1^{\circ}$ Encontro: Primeiras Concepções; $2^{\circ}$ Encontro: Condutores ou Isolantes?; $3^{\circ}$ Encontro: Circuitos Elétricos; $4^{\circ}$ Encontro: Corrente Elétrica e Resistência; $5^{\circ}$ Encontro: Elétrons, Corrente Elétrica e Diferença de Potencial.

De modo geral, a intenção foi saber quais são as pré-concepções dos estudantes com relação ao tema Eletricidade, verificar até que ponto os alunos conseguem identificar os diferentes materiais e diferenciar os circuitos fechados dos abertos.

Quanto aos sujeitos da pesquisa, contou-se com a participação de seis alunos com idades entre 20 e 35 anos. Destes, três com deficiência visual congênita, dois perderam a visão e um com baixa visão.

A sequência piloto apresentou dois principais objetivos. O primeiro, desenvolver as categorias de análise, construídas a partir das relações aluno-conhecimento mediadas pelos materiais didáticos e procedimentos utilizados. O segundo, analisar e avaliar os limites e possibilidades do material e do procedimento metodológico utilizado, visando a sua 
reestruturação para a elaboração e aplicação de uma segunda sequência, capaz de ser aplicada junto a estudantes com e sem deficiência visual (EVANGELISTA, 2008).

\subsection{Categorias de Análise}

Adotamos duas categorias de análise - Descrição dos Materiais e Apreensão do Conteúdo, assim entendidas:

- Descrição dos Materiais - Indica se os materiais são facilmente identificados e se oferecem as condições necessárias para a realização das atividades experimentais da sequência de ensino. Para melhor detalhar esta categoria, sua fundamentação ocorrerá por meio de três subcategorias.

- Operacionalização do material - Até que ponto os materiais apresentados facilitam sua identificação.

- Descrição de eventos - Verificar se ocorre o manuseio dos materiais e equipamentos com facilidade, com a intenção de realizar algum evento (circuito fechado, circuito aberto).

- Propostas de atividades - Verificar se as propostas manifestas pelos alunos quanto à realização ou aperfeiçoamentos de atividades.

- Apreensão do Conteúdo - Observar se os procedimentos utilizados nas atividades auxiliam os estudantes a expressarem seu poder de análise e interpretação das diferentes situações estudadas. Para melhor detalhar esta categoria, sua fundamentação ocorreu por meio de quatro subcategorias.

- Construindo hipóteses - Classificar as hipóteses elaboradas pelos alunos sobre o assunto estudado.

- Compartilhando conceitos - Averiguar quando o aluno reage a uma hipótese ou pergunta, respondendo por meio de uma frase, palavra ou expressão, corroborando com o que o professor ou colega expôs.

- Questionando conceitos - Identificar o questionamento dos estudantes através de hipóteses ou perguntas, motivadas por questões vindas do professor ou colegas.

- Relação de conceitos com o cotidiano - Classificar o momento onde o estudante contextualiza o fenômeno estudado. 
Desta forma, assumiu-se que, para o aluno assimilar os conceitos, ele deveria elaborar hipóteses, compartilhar e/ou questionar os conceitos trabalhados, além de contextualizar os fenômenos estudados em sala.

\subsection{Procedimentos}

O procedimento utilizado apoiou-se nas contribuições de Masini (1994) e Vygotski (1998). O primeiro, por afirmar serem os sentidos tátil, auditivo, olfativo e do paladar, os mediadores na construção interna de uma noção do mundo externo por estas pessoas. $O$ segundo, por descrever que nestes sujeitos, existe um aumento da memória, da atenção e das atitudes verbais, através do desenvolvimento de uma sobre-estrutura psíquica, derivada de muito esforço e exercício. Associados a estes, apresentaram-se ainda a dimensão sinestésica, progressiva e de memória de reconhecimento tátil-auditivo (HALL, 1981 apud MASINI, 1994), além da necessidade do reconhecimento do ambiente (SOUZA, 2002) e da disposição espacial em que os objetos se encontravam.

Neste viés, resolveu-se entregar o material das atividades aos alunos, para que pudessem ter a noção do que estava ocorrendo em cada momento do encontro, permitindo um período maior para a aquisição dos dados táteis e certa proximidade com o evento ou objeto analisado. A fim de facilitar a familiarização do estudante com os materiais, empregou-se aqueles mais usualmente utilizados no cotidiano, como madeira, metal e papelão. Quando havia a necessidade do uso de equipamentos mais complexos, os alunos realizavam um detalhado reconhecimento tátil do mesmo antes de utilizá-lo.

A disposição espacial dos materiais não era alterada durante as aulas, proporcionando ao estudante a certeza de que o material posto em um determinado local permaneceria ali até que fosse necessária a sua retirada. Ao retirar ou inserir algum novo elemento ao ambiente, primeiramente informava-se o que iria ocorrer, para então realizar as mudanças.

\subsection{MATERIAIS DIDÁticos}

Dentre os equipamentos, optou-se pela utilização de um componente eletrônico chamado buzzer (figura 1a), o qual se comporta de maneira similar a um diodo, permitindo a passagem de corrente elétrica em um sentido e no outro, não. Quando a passagem da corrente se dá no sentido correto, ele emite um som semelhante a uma sirene, sendo sua intensidade sonora diretamente proporcional à intensidade da corrente elétrica que o percorre. Pelo fato de ter uma polaridade definida, colocou-se um nó na extremidade positiva. 
Foi construído um tabuleiro (figura 1d) para auxiliar na montagem de circuitos elétricos. Este equipamento oferece total segurança aos estudantes, evitando a exposição de pontas e cantos afiados. Foi projetado para ser desmontável, sendo constituído por três partes, para que os alunos pudessem montar e desmontar os circuitos sem a intervenção docente.

Figura 1 - Buzzer e Tabuleiro

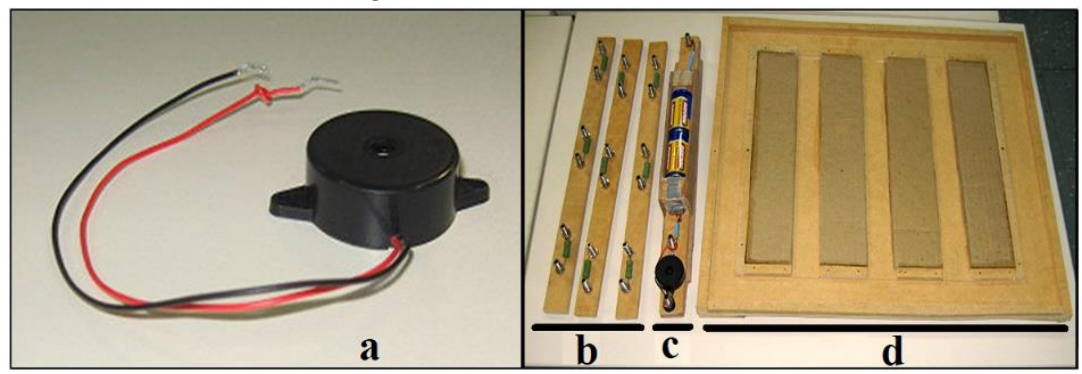

Fonte: Das atividades realizadas (2018).

A primeira parte (figura 1b) foi composta por três tiras de madeira retangulares com três resistores cada, fixados através de pinos de metal. Os três resistores de cada régua tinham a finalidade de induzir ao aluno a ideia de circuito série. A segunda parte (figura 1c), denominada porta-pilhas, tratava-se de uma tira de madeira retangular, com um pino de metal em cada extremidade, que determinavam o ponto de partida e chegada do circuito. Na parte central da régua, havia uma caixa para duas pilhas médias e um buzzer, já fixado. A inserção do buzzer junto ao compartimento das pilhas ocorreu devido a sua polaridade definida. A terceira (figura 1d), denominada base, teve a função auxiliar na montagem de um circuito série ou paralelo através dos desníveis e superfícies com aderências diferentes. As partes altas foram feitas de papelão áspero; as partes baixas, de madeira lisa, para auxiliar através do tato nos encaixes das outras partes do equipamento. A intenção foi induzir os estudantes a colocarem os componentes nos vãos existentes. Colocados no centro, formava-se um circuito paralelo, colocados nas bordas, um circuito série.

Para fixar as três partes, foram inseridos grampos de metal em formato de "U" (figura 2a) e, para interligar o circuito, foram utilizados fios com conectores "pino banana" em suas extremidades. 
Figura 2 - Tabuleiro Montado e Maquetes

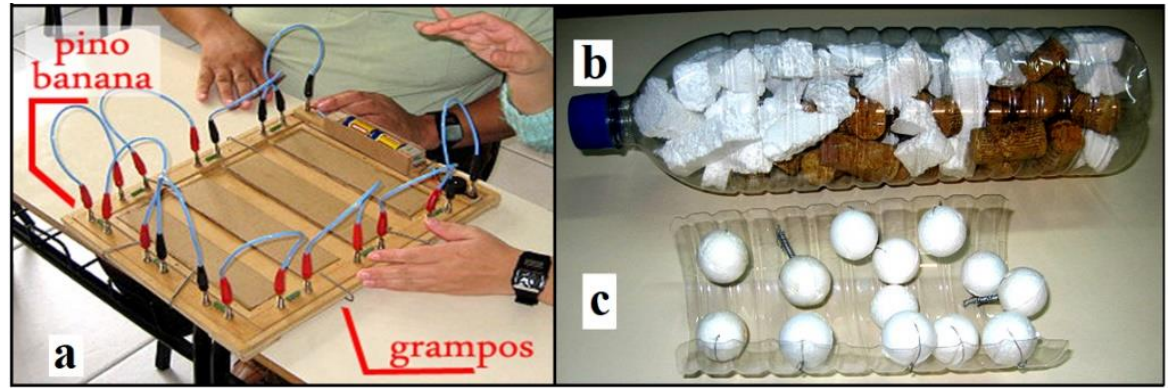

Fonte: Das atividades realizadas (2018).

Foram acrescentadas duas maquetes (figura $2 \mathbf{b}$ ), desenvolvidas no intuito de facilitar a indução do conceito clássico da estrutura cristalina de um fio condutor e da corrente elétrica.

A primeira (figura 2c) fez analogia com o fio condutor em circuito aberto. Era composta por uma garrafa PET, com pedaços de isopor e rolhas de cortiça em seu interior. Os alunos, ao "chacoalhá-la", percebiam auditivamente a existência de partes soltas. A intenção era que, conduzidos pelo professor, conseguissem fazer uma analogia aos elétrons livres no fio. A segunda(figura 2c), consistiu em uma garrafa PET, cortada longitudinalmente ao meio, com esferas de isopor fixadas com arame em seu interior. Estas esferas simulavam os átomos. Os alunos foram convidados a entre passá-los com os dedos de "ponta a ponta", assumindo a função dos elétrons livres. Com isso, pretendeu-se construir uma analogia da movimentação dos elétrons livres em um fio condutor submetido a uma diferença de potencial elétrico, além de relacionar a resistência elétrica às partículas existentes no trajeto.

\subsection{EM SÍNTESE}

As Atividades Experimentais mostraram-se adequadas ao ensino de Eletrodinâmica para os sujeitos em questão. A Compartilhada oportunizou que, a partir de um mesmo elemento, os alunos chegassem a respostas semelhantes. A Modelizadora utilizou-se das maquetes para auxiliar na indução do conceito corrente elétrica. A Crítica permitiu a diferenciação dos conceitos corrente elétrica, energia elétrica e diferença de potencial elétrico. A Comprobatória auxiliou na fixação dos conceitos por meio das revisões realizadas.

Os alunos referiram-se a elementos do seu cotidiano, questionaram as explicações realizadas pelos colegas, compartilharam concepções e construíram hipóteses. Isto se deve, em parte, à opção metodológica adotada: materiais entregues progressivamente e sucessivas revisões. O professor procurou ainda dar voz aos estudantes, visando com isto, provocar questionamentos e promover situações que fomentem a troca e a construção de hipóteses. 
Todos os materiais foram reconhecidos tatilmente. Inicialmente, a inserção do buzzer provocou certa dificuldade em sua utilização, porém, com suas repetidas solicitações, foi bem aceito pelos alunos. A robustez das partes do tabuleiro também obteve relevância, permitindo que os alunos manuseassem os mesmos, sem receio de quebrá-los ou danificá-los. As duas maquetes se mostraram eficazes, auxiliando nas analogias por meio da identificação tátil e descrição dos materiais.

No entanto, os termos/conceitos científicos não foram assimilados a contento. A ordem da sequência didática apresentou limitações, pois o conceito de corrente elétrica foi abordado apenas no último encontro. Houve ainda a contaminação das respostas orais dos alunos pelos colegas. O tempo despendido para o reconhecimento do tabuleiro foi muito grande e a liberdade dos alunos ficou comprometida, dificultando a realização de ações voluntárias e sugestões espontâneas de novas configurações para o circuito.

Tendo em vista um ambiente onde alunos com e sem deficiência visual convivam, a reestruturação da sequência didática se faz indispensável. Deve-se ter equipamentos e estratégias metodológicas que utilizem ambos os sentidos, tato e visão, e equiparem o tempo de reconhecimento dos materiais e as realizações das atividades, ou pelo menos, minimizem esta discrepância. Com base nessa perspectiva foi reorganizada a sequência didática como se observa a seguir.

\section{REAdEQUAÇões da SEQUÊNCIA PROPOSTA E DOS MATERIAIS}

A partir das observações e registros no ensaio piloto, nosso maior objetivo foi reestruturar os equipamentos e os procedimentos metodológicos, de modo a permitir sua utilização tanto por alunos com deficiência visual quanto por videntes, isto é, em classe regulares. Para isto, fez-se alterações, resultando num plano de aulas composto por cinco encontros de uma hora de duração, culminando em uma avaliação final, realizada separadamente com cada aluno em horários diferentes. Os encontros foram realizados semanalmente, nas segundas e quintas-feiras. A nova sequência didática e as alterações propostas em relação ao ensaio piloto estão na tabela abaixo, para efeitos comparativos: 
Quadro 1 - Encontros

\begin{tabular}{|c|c|}
\hline Ensaio Piloto & Nova Sequência Didática \\
\hline $1^{\circ}$ Encontro: Primeiras Concepções. & $1^{\circ}$ Encontro: Primeiras Concepções. \\
\hline $2^{\circ}$ Encontro: Condutores ou Isolantes? & $\begin{array}{l}2^{\circ} \text { Encontro: Condutores ou Isolantes, Circuito } \\
\text { Fechado ou Aberto? }\end{array}$ \\
\hline $3^{\circ}$ Encontro: Circuitos Elétricos. & $3^{\circ}$ Encontro: A Corrente Elétrica em Nível Atômico. \\
\hline $\begin{array}{l}4^{\circ} \text { Encontro: Corrente Elétrica e Resistência } \\
\text { Elétrica. }\end{array}$ & $\begin{array}{l}4^{\circ} \text { Encontro: Corrente Elétrica, Resistência Elétrica e } \\
\text { Diferença de potencial elétrico. }\end{array}$ \\
\hline $\begin{array}{l}5^{\circ} \text { Encontro: Elétrons, Corrente Elétrica e } \\
\text { Diferença de potencial elétrico. }\end{array}$ & $5^{\circ}$ Encontro: Circuitos Elétricos Residenciais. \\
\hline Não houve uma avaliação final. & Avaliação. \\
\hline
\end{tabular}

Fonte: Das atividades realizadas (2018).

Nesta sequência, trabalhamos com 4 alunos com idades entre 19 e 24 anos, todos voluntários. Três deles perderam a visão quando ainda crianças e um apresenta baixa visão (5\%). Adiante serão apresentados detalhes sobre as modificações realizadas no procedimento metodológico e nos materiais didáticos.

\subsection{Procedimentos}

Além das estratégias metodológicas já citadas, inseriram-se outras duas. A "leitura interativa" e o uso de tampas de garrafa pet na aplicação dos questionários.

Quanto à leitura, utilizou-se de textos retirados do GREF (1991). O intuito foi já inserir os termos científicos a partir do primeiro encontro, a fim de torná-los mais familiares aos estudantes. Durante a leitura, o professor oportunizava interações, promovendo constantes momentos que requisitavam a participação ativa dos estudantes durante a leitura. Deste modo, proporcionou-se uma "leitura interativa", conduzindo os alunos à condição de agentes ativos no processo. Este procedimento surgiu como uma alternativa, a fim de manter os alunos atentos, relacionando o conceito lido com os materiais e atividades realizadas, procurando desta forma, auxiliar na elucidação dos significados terminológicos, eventos e relações Físicas.

Os questionários, retirados de Evangelista (2019), lidos pelo professor aos alunos, apresentaram o objetivo de revisar o assunto tratado no encontro anterior, revisar o assunto trabalhado ao fim do encontro atual e levantar as hipóteses discentes antes da montagem dos circuitos. As respostas foram obtidas por intermédio de três tampas de garrafa PET, postas sobre a mesa, que representaram as alternativas a, b e c. A tampa referente à alternativa escolhida como resposta deveria ser virada ao contrário pelo estudante (boca para cima). Deste modo, 
além de inibir a contaminação das respostas dos alunos pelos colegas, atribuiu-se um caráter dinâmico, divertido e descontraído aos questionários.

\subsection{MATERIAIS DIDÁtICOS}

Os materiais foram totalmente reconfigurados, porém, respeitando as características tidas como pertinentes; indução quanto a sua montagem, liberdade no seu manuseio, segurança, resistência mecânica e durabilidade. A seguir, as principais modificações realizadas para a nova sequência didática.

O limite espacial oferecido pelo tabuleiro foi transferido para a mesa do aluno através de tiras de borracha E.V.A fixadas em suas bordas (Em rosa na figura 3a). A ênfase atribuída à contextualização dos assuntos trabalhados, contou com o auxílio de aparelhos e equipamentos eletroeletrônicos utilizados em todos os encontros: chuveiros elétricos, motores elétricos corrente continua (CC) de doze volts, rádios $\mathrm{CC}$ de três volts, ebulidores elétricos, tomadas, fios com plug's e interruptores (figura 3b).

Figura 3 - Limite da mesa e eletro-eletrônicos

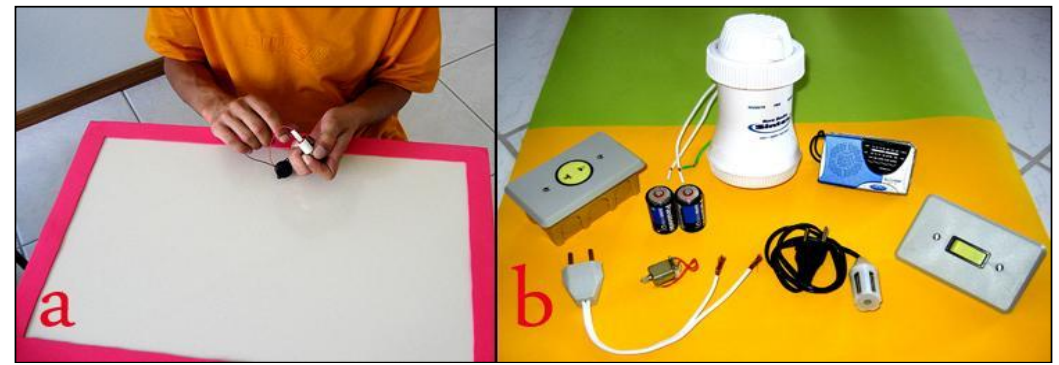

Fonte: Das atividades realizadas (2018).

Ao se tratar das fontes, foram utilizadas tomadas elétricas residenciais (figura 4b), compostas por duas pilhas ligadas em série (figura 4b1), fixadas atrás da tomada por uma capa plástica (figura 4b2). O pólo positivo foi indicado com fita crepe (figura 4b3). Também houve modificação no porta-pilhas (figura 4a), inserindo dois conectores RCA fêmeas nas extremidades. 
Figura 4 - Fontes elétricas

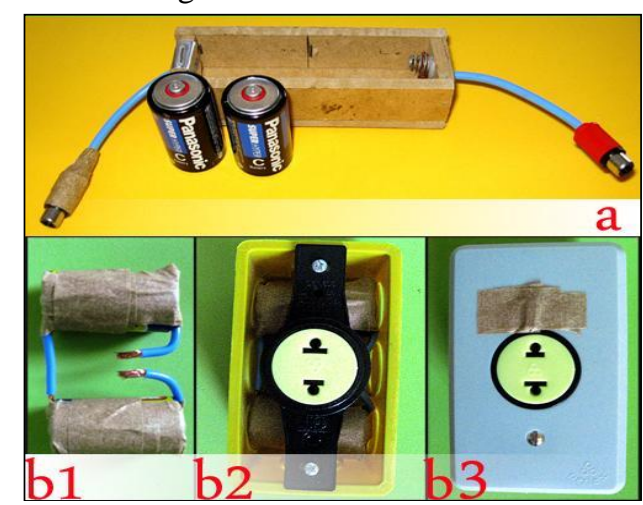

Fonte: Das atividades realizadas (2018).

Aos interruptores (figura 5a), fio com plug (figura 5b) e tomadas (figura 5c) foram acrescentados dois conectores RCA fêmeas nas extremidades. Os interruptores e as tomadas foram apresentados de maneira a permitir que seus terminais de conexão fossem percebidos tatilmente. A região referente à parte positiva foi indicada com fita crepe.

Figura 5 - Interruptores, fio com plug e tomadas

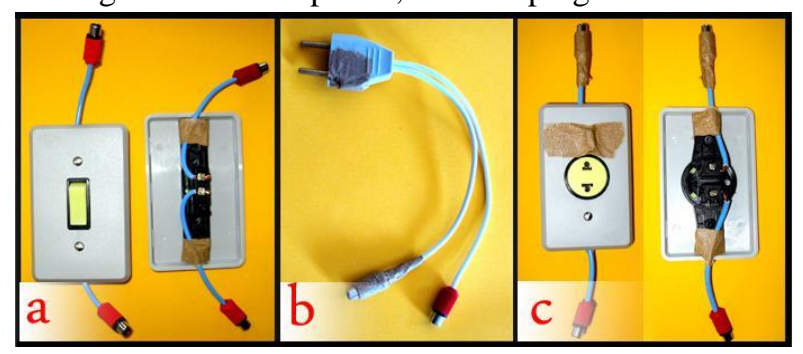

Fonte: Das atividades realizadas (2018).

O buzzer (figura 6a) foi empregado separadamente nas atividades, com dois conectores RCA fêmea. Ao rádio (figura 6 b) foi inserido um fio com plug, para permitir sua conexão à tomada. Em ambos os casos, a polaridade positiva foi identificada com fita crepe.

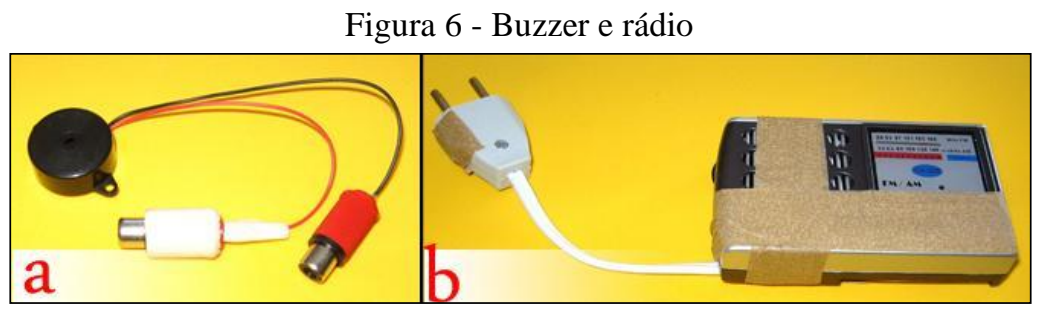

Fonte: Das atividades realizadas (2018).

Os resistores (figura 7c) foram apresentados de forma independentes, por meio de duas resistências distintas, representadas pelas diferentes aderências, provindas de cilindros feitos com papel-lixa. 
Figura 7 - Conectores e Resistores

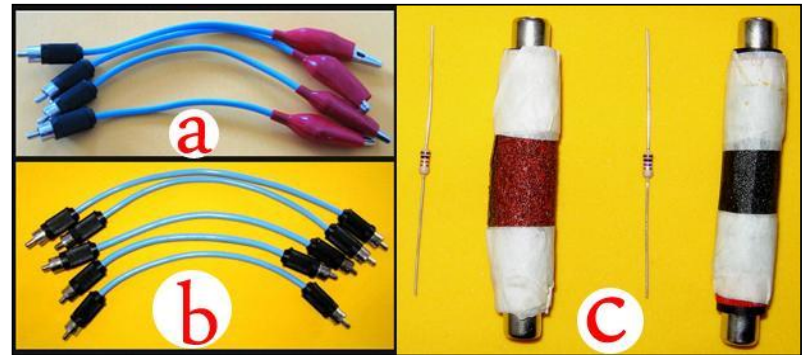

Fonte: Das atividades realizadas (2018).

O "resistor modificado" possuía um resistor no interior do cilindro. Os conectores tipo "pino banana" foram substituídos por conectores RCA, utilizados em dois tipos de fios para conexões entre circuitos. Um deles com extremidade jacaré-RCA (figura 7a) e, o outro, com extremidades RCA-RCA (figura 7b).

As maquetes dos fios condutores (figura 8b) foram unificadas em um único cilindro de papel, oferecendo condições para que se realizassem analogias com fios submetidos, ou não, a uma diferença de potencial elétrico. Composta por um canudo de papelão, esta maquete foi projetada para ser aberta (figura 8a). Em seu interior havia esferas de isopor fixas, representando os átomos e grãos de milho, que representam os elétrons. Estes também foram representados pelos dedos dos estudantes ao perpassarem o canudo de ponta a ponta.

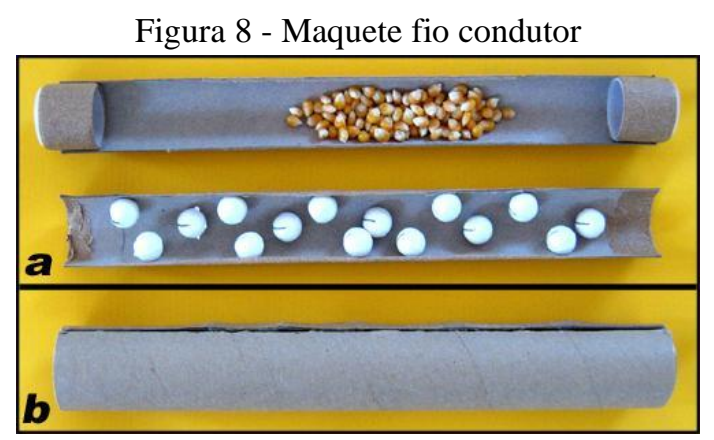

Fonte: Das atividades realizadas (2018).

Outras duas novas maquetes desenvolvidas consistem em dois tubos de papel-cartolina, com grãos de feijão no seu interior. As analogias com as diferentes resistências elétricas foram feitas por meio da aderência externa.

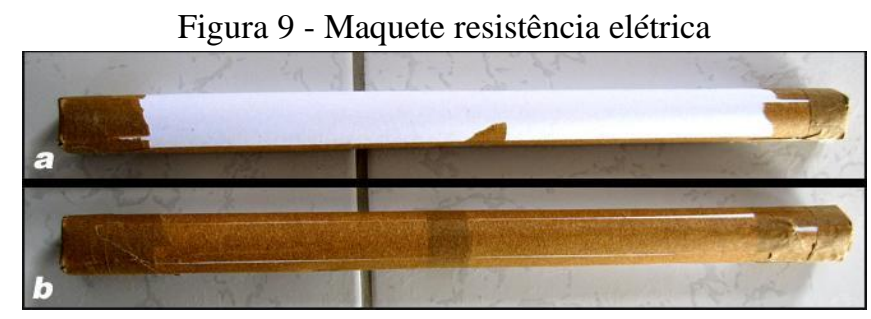

Fonte: Das atividades realizadas (2018). 
A "maquete a" referente à menor resistência elétrica (figura 9a), apresentava-se externamente lisa. Já, a "maquete b", relativa à maior resistência elétrica (figura 9b), possuía fita crepe em seu entorno. A resistência mecânica oferecida ao movimento dos grãos na "maquete a" decorria do atrito existente entre os grãos e o papel-cartolina. Na "maquete b", a resistência mecânica procedia de rugosidades feitas com fita crepe, inseridas em toda a sua extensão interna. O movimento dos grãos era percebido de maneira tátil e auditiva através do atrito com a cartolina.

A seguir mostraremos os circuitos montados pelos estudantes;

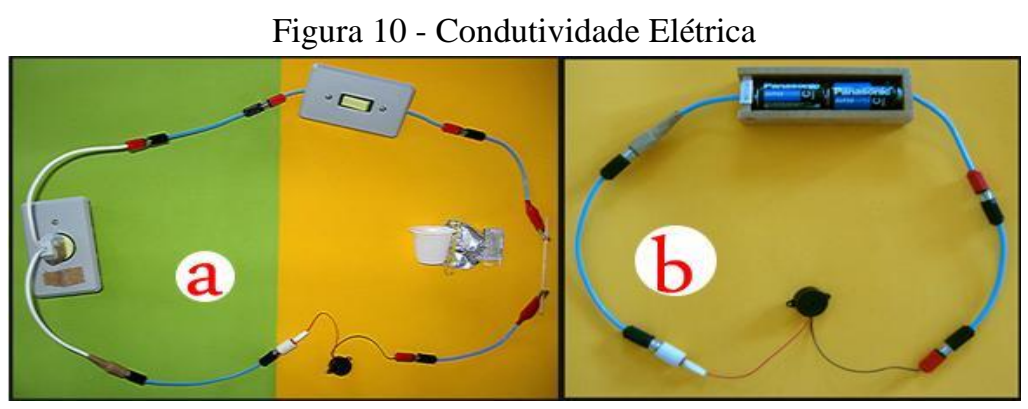

Fonte: Das atividades realizadas (2018).

Figura 11 - Circuitos série e paralelo

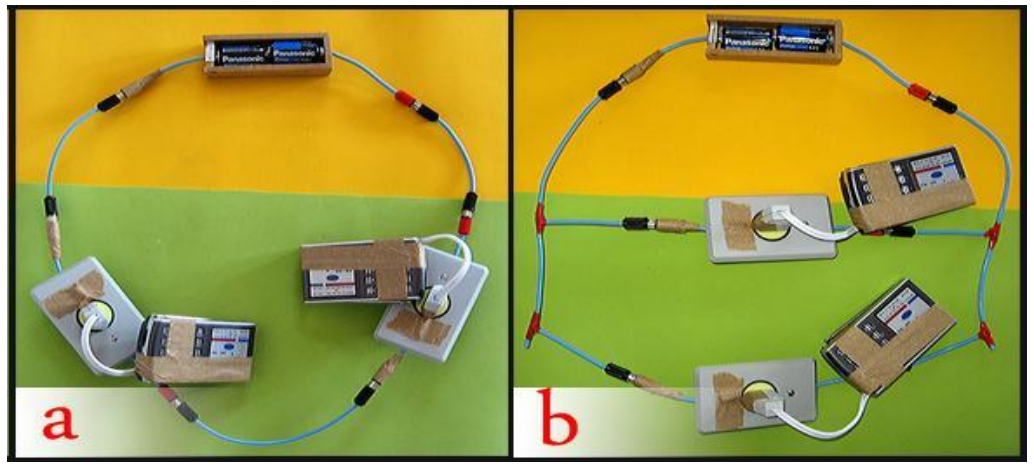

Fonte: Das atividades realizadas (2018).

Figura 12 - Atividade com circuitos série

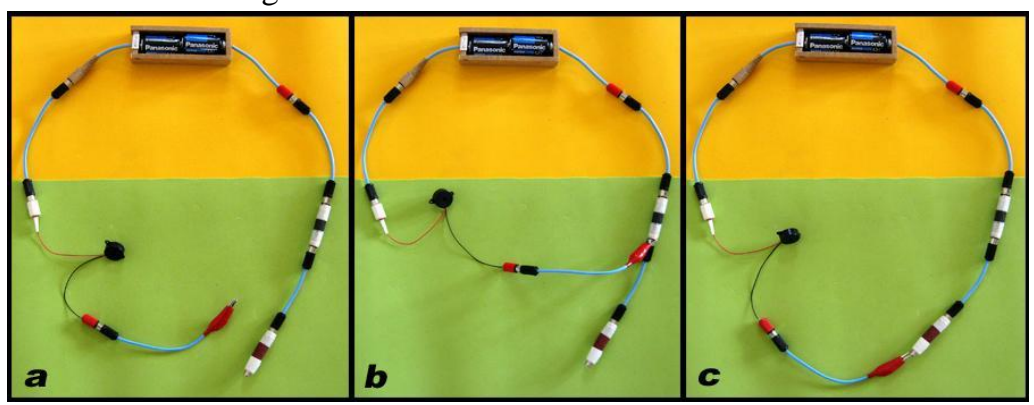

Fonte: Das atividades realizadas (2018). 
A figura 10a, mostra o circuito construído para identificar a condutividade elétrica dos materiais,abertura e fechamento do circuito. Na figura $\mathbf{1 0 b}$, está o circuito no qual os alunos praticaram a inserção do buzzer, atentando para sua polaridade definida. Os circuitos série e paralelo estão representados nas figuras 11a e 11b, onde foi evidenciada a constância da corrente elétrica no primeiro e, da diferença de potencial elétrico, no segundo. A figura 12 retrata a atividade em que se trabalhou a relação entre resistência elétrica e corrente elétrica, tornando nítido que o aumento do valor da primeira resulta na redução do valor da segunda, percebido na atividade, por meio da variação sonora emitida pelo buzzer.

Havendo interesse em aprofundamento da leitura no assunto, Evangelista (2019) apresenta mais detalhes dos relatos e análises dos alunos com deficiência visual sobre as atividades aplicadas neste trabalho.

\section{CONSIDERAÇÕES FINAIS E PERSPECTIVAS}

A mudança na ordem da sequência didática apresentou melhores resultados. Ao tratar dos conceitos circuitos abertos e fechados juntamente com a condutividade dos materiais, favoreceu-se a inter-relação conceitual, auxiliando na apreensão dos saberes. Por trabalhar o conceito corrente elétrica mais cedo, foi possível recorrer às terminologias científicas com maior frequência, auxiliando inclusive na contextualização dos fenômenos, estimulado por meio dos circuitos elétricos residenciais.

Através dos questionários, além de se detectar as assimilações e os equívocos, reforçouse os assuntos pendentes através de explicações e constantes recapitulações conceituais, resultando na redução das disparidades conceituais e minimização das dificuldades de aprendizado oriundas da ausência de um estudo extra-classe. A utilização de textos didáticos (GREF, 1991), auxiliou na inserção e compreensão da terminologia científica. A "leitura interativa" demonstrou-se eficaz, visto que, ao atribuir uma condição participativa aos estudantes, estes mantinham-se atentos durante a leitura, relacionando os conceitos lidos com ações concretas, requisitadas simultaneamente pelo professor.

A constatação das subcategorias de Apreensão do Conteúdo mostrou que os alunos apresentaram uma participação ativa no processo de ensino e aprendizagem, expressando suas ideias, provocando questionamentos e promovendo situações de conflitos e compartilhamentos conceituais. A identificação das subcategorias de Descrição do Material mostrou que houve uma boa aceitação dos materiais por parte dos alunos, que manusearam e realizaram as ações solicitadas sem maiores dificuldades. Verificou-se ainda que, o fato de os materiais terem sidos 
apresentados separadamente, permitiu um reconhecimento tátil mais rápido, atribuindo ainda maior liberdade durante a montagem dos circuitos. Como consequência, os alunos propuseram mais atividades espontaneamente.

Constatou-se que, para o processo de caráter inclusivo, tanto os materiais quanto os procedimentos apresentaram-se potencialmente capazes de serem aplicados junto a alunos, com e sem deficiência visual, estudando no mesmo ambiente do ensino regular, uma vez que o tempo despendido para o reconhecimento dos materiais foi reduzido, a liberdade atribuída ao aluno aumentada, permitindo a realização de ações voluntárias e sugestões espontâneas de novas configurações para os circuitos. Oportunizaram-se ainda, situações nas quais o "erro", durante a montagem dos circuitos, também fosse utilizado para fomentar soluções. Estas, por sua vez, pareceram potencializar o poder argumentativo discente, em que constantemente mencionavam eventos e materiais já trabalhados. Além disso, as relações com o cotidiano e a fixação dos termos científicos foram verificadas com maior frequência.

Por outro lado, alguns limites percebidos durante a realização desta pesquisa precisam ser apontados. Não foi utilizada a aplicação de equações matemáticas, contudo, acredita-se que o primeiro passo foi dado. A partir do que foi trabalhado, torna-se possível sugerir situações hipotéticas para serem resolvidas matematicamente. As recomendações quanto aos materiais e procedimentos metodológicos precisam ser postas em prática para verificar seu real potencial.

Ademais, há uma necessidade de desenvolvimento de critérios referentes à técnicas avaliativas que sejam condizentes com as necessidades e especificidades dos estudantes a fim de ser possível mensurar mais detalhadamente o desenvolvimento educacional. Além disso, durante a presença na ACIC verificou-se que os respectivos alunos tinham contato direto com computadores pessoais, tornando nítida a necessidade de investigar estratégias que permitam utilizar as tecnologias e os multimeios como auxílio no processo de ensino e aprendizagem destes sujeitos. Pode-se salientar ainda, a necessidade de transpor didaticamente os conteúdos trabalhados, para que permitam promover o desenvolvimento do pensamento crítico, criando procedimentos metodológicos que motivem a inserção da literatura específica, no intuito de auxiliar a assimilação conceitual e terminológica.

Finalmente, nesta perspectiva, este trabalho procurou mostrar que é possível tratar conceitos complexos e/ou específicos com estudantes com deficiência visual e que, potencialmente falando, o ensino destes, juntamente com alunos videntes, parece plausível. 


\section{REFERÊNCIAS}

ALVES FILHO, José de Pinho. Atividades Experimentais: do Método à Prática Construtivista. 2000. 302 f. Florianópolis: Tese (Doutorado em Educação: Ensino de Ciências Naturais) - Universidade Federal de Santa Catarina, Florianópolis, 2000. Disponível em: https://repositorio.ufsc.br/xmlui/handle/123456789/79015. Acesso em: 14 jan. 2021.

BRASIL. Ministério da Educação. Lei de Diretrizes e bases da educação (n.939496). Brasília, DF, 1996. Disponível em: http://portal.mec.gov.br/arquivos/pdf/ldb.pdf]. Acesso em: 14 jan. 2021.

CAMARGO, Eder Pires de. O Ensino de Física no Contexto da Deficiência Visual: elaboração e Condução de Atividades de Ensino de Física para Alunos Cegos e com Baixa Visão. 2018. 272 f. Campinas: Tese (Doutorado em Educação para a Ciência) Faculdade de Educação, Universidade Estadual de Campinas, 2005. Disponível em: http://repositorio.unicamp.br/jspui/handle/REPOSIP/252902. Acesso 14 jan. 2021.

CARNEIRO, Eudocha et al. EXPERIMENTO ADAPTADO PARA ESTUDANTES COM DEFICIÊNCIA VISUAL: ESTUDO DA RELAÇÃO SOLUBILIDADE VERSUS TEMPERATURA. Revista Areté| Revista Amazônica de Ensino de Ciências, v. 9, n. 18, p. 173-181, 2017. Disponível em: http://periodicos.uea.edu.br/index.php/arete/article/view/214. Acesso em: 14 jan. 2021

CAT-Comitê De Ajudas Técnicas. Ata da Reunião VII, de dezembro de 2007 do Comitê de Ajudas Técnicas. Secretaria Especial dos Direitos Humanos da Presidência da República (CORDE/SEDH/PR), 2007. Disponível em:

https://www.assistiva.com.br/Ata_VII_Reunião_do_Comite_de_Ajudas_Técnicas.pdf. Acesso 14 jan. 2021.

COLL, César; POZO, Juan Ignacio; SARABIA, Barnabé; VALLS, Enric. Os conteúdos na reforma: ensino e aprendizagem de conceitos, procedimentos e atitudes. Porto Alegre: Artmed, 2000

DE SOUZA, Flaviane Cristine Santos; PALMA, Francisco Rodrigo Chagas. Proposta de um sistema de representação da reflexão da luz em um espelho esférico para alunos com deficiência visual. Revista Areté| Revista Amazônica de Ensino de Ciências, v. 9, n. 20, p. 67-71, 2017. Disponível em: http://periodicos.uea.edu.br/index.php/arete/article/view/247. Acesso em: 14 jan. 2021.

DRIVER, Rosalind. Psicologia cognitiva y esquemas conceptuales de los alumnos. Enseñanza de lãs Ciências, v.4, n.1, p.3-15, 1986. Disponível em: https://www.raco.cat/index.php/Ensenanza/article/view/50854. Acesso em 14 jan. 2021.

EVANGELISTA, Fábio Lombardo. O ensino de corrente elétrica a alunos com deficiência visual. 2008. 198f. Florianópolis: Dissertação (Mestrado em Educação Científica e Tecnológica). Universidade Federal de Santa Catarina, Florianópolis, 2008. Disponível em: https://repositorio.ufsc.br/xmlui/handle/123456789/91552. Acesso em 14 jan. 2021.

EVANGELISTA, Fábio Lombardo. Física para pessoas com deficiência visual: ensino de corrente elétrica- Volume 1. 1 ed. Concórdia: Jucimar Peruzzo, 2019. 
FACCIO, Miguel. et al. Força e movimento: concepções alternativas no Ensino Superior. Revista Educar Mais, v. 3, n. 2, p. 173-191, 2019.

FREITAS, Wesley Ricardo de Souza; JABBOUR, Charbel José Chiappetta. O Estudo de Caso (s) como Estratégia de Pesquisa Qualitativa: fundamentos, roteiros de aplicação e pressupostos de excelência. In: XXX ENCONTRO NACIONAL DE ENGENHARIA DE PRODUÇÃO, 2010, São Carlos: UFSCAR, 2010. Disponível em: http://www.abepro.org.br/biblioteca/enegep2010_tn_sto_122_790_15342.pdf. Acesso em 14 jan. 2021.

GALVÃO FILHO, Teófilo Alves. Tecnologia assistiva para uma escola inclusiva: apropriação, demanda e perspectivas. 2009. 346f. Salvador: Tese (Doutorado em Educação)- Universidade Federal da Bahia, Salvador, 2009. Disponível em: https://repositorio.ufba.br/ri/bitstream/ri/10563/1/Tese\%20Teofilo\%20Galvao.pdf. Acesso em 14 jan 2021.

GIL, Antonio Carlos. Como elaborar projetos de pesquisa. 4ª ed. São Paulo: Atlas, 2002.

GRECA, Ileana Maria; MOREIRA, Marco Antonio. Além da detecção de modelos mentais dos estudantes: uma proposta representacional integradora. Investigações em Ensino de Ciências, v. 7, n.1, 2002. Disponível em: https://www.if.ufrgs.br/cref/ojs/index.php/ienci/article/view/568/360. Acesso em 14 jan. 2021.

GRUPO DE REELABORAÇÃO DO ENSINO DE FÍSICA. Eletromagnetismo. São Paulo: Edusp, 1998. Disponível em: www.if.usp.br/gref/eletromagnetismo.html. Acesso em: 15jan. 2021.

HOFFMANN, Jairo Luiz; NAHIRNE, Ana Paula; STRIEDER, Dulce Maria. Um diálogo sobre as concepções alternativas presentes no ensino das ciências. Arquivos do Museu Dinâmico Interdisciplinar, v. 21, n. 3, p. 90-101, 2017. Disponível em: http://www.periodicos.uem.br/ojs/index.php/ArqMudi/article/view/40944/pdf. Acesso em 14 jan. 2021.

LIMA, Maria da Conceição Barbosa; CASTRO, Giselle Faur de. Formação inicial de professores de Física: a questão da inclusão de alunos com deficiências visuais no ensino regular. Ciência e Educação, v. 18, n. 1, p. 81-98, 2012. Disponível em: https://www.scielo.br/pdf/ciedu/v18n1/06.pdf. Acesso em 14 Jan 2021

MASINI, Elcie Aparecida Fortes Salzano. Impasses sobre o Conhecer e o Ver. In: O perceber e o relacionar-se do deficiente visual: orientando professores especializados. Brasília: CORDE, 1994.

OLIVEIRA, Dirlene Aparecida de. Concepções espontâneas sobre o conceito de movimento entre estudantes de física (mecânica) da UFFS-Campus Laranjeiras do Sul. 2018. 47f. Laranjeiras do Sul: Monografia (Conclusão de curso de Licenciatura Interdisciplinar em Educação do Campo)- Universidade Federal da Fronteira Sul, 2018. Disponível em: https://rd.uffs.edu.br/bitstream/prefix/2956/1/OLIVEIRA.pdf. Acesso em 14 jan. 2021. 
PIETROCOLA, Mauricio. Construção e realidade: o papel do conhecimento físico no entendimento do mundo In: PIETROCOLA, M. (Orgs). Ensino de Física: conteúdo, metodologia e epistemologia numa concepção integradora. Florianópolis: Editora da UFSC, 2001.

PIMENTEL, Andréia Guerra; ARAGON, Glauca Torres. JOGO EDUCACIONAL E MEIO AMBIENTE: ADAPTAÇÃO DE UM LIVRO-JOGO PARA ALUNOS COM DEFICIÊNCIA VISUAL. Revista Areté| Revista Amazônica de Ensino de Ciências, v. 11, n. 24, p. 156165, 2019. Disponível em: http://periodicos.uea.edu.br/index.php/arete/article/view/1540/961. Acesso em: 14 jan. 2021.

SANTOS, Pâmela Mello dos. Evolução biológica na perspectiva de estudantes do ensino médio: das concepções espontâneas aos saberes escolares. 2017.118f. Santa Maria: Dissertação (Mestrado em Educação em Ciências)- Universidade Federal de Santa Maria, Santa Maria, 2017. Disponível em: https://repositorio.ufsm.br/bitstream/handle/1/14092/DIS_PPGEC_2017_SANTOS_PAMEL A.pdf?sequence=1eisAllowed=y. Acesso em: 14 jan. 2021.

SOLIS VILLA, R. Ideas intuitivas y aprendizaje de las ciencias. Enseñanza de las Ciencias, v.2, n.2, p.1-19, 1984.

SOUZA, Olga Solange Herval. Nas entrelinhas da inclusão escolar de alunos com necessidades educativas especiais: o desafio da formação docente. 2002. 194 f. Porto Alegre: Tese (Doutorado em Educação) Faculdade de Educação, Universidade Federal do Rio Grande do Sul, 2002.

VIENNOT, Laurence. Spontaneous reasoning in elementary dynamics. European Journal of Science Education, v.1, n.2, p.205-221, 1979.

VYGOTSKI, Lev Semionovitch. Obras escogidas- III. Problemas del desarrollo de la psique. $1^{\text {a }}$. ed. Madrid: A. Machado Libros S. A, 2013. 